University of Nebraska - Lincoln

DigitalCommons@University of Nebraska - Lincoln

Faculty Publications, Department of Psychology

Psychology, Department of

10-1-1987

\title{
Congruence between Objective and Self-Report Data in a Sample of Young Adolescents
}

\author{
Lisa J. Crockett \\ University of Nebraska-Lincoln, ecrockett1@unl.edu \\ John E. Schulenberg \\ Purdue University \\ Anne C. Petersen \\ Pennsylvania State University, annepete@umich.edu
}

Follow this and additional works at: https://digitalcommons.unl.edu/psychfacpub

Part of the Psychiatry and Psychology Commons

Crockett, Lisa J.; Schulenberg, John E.; and Petersen, Anne C., "Congruence between Objective and SelfReport Data in a Sample of Young Adolescents" (1987). Faculty Publications, Department of Psychology. 250.

https://digitalcommons.unl.edu/psychfacpub/250

This Article is brought to you for free and open access by the Psychology, Department of at DigitalCommons@University of Nebraska - Lincoln. It has been accepted for inclusion in Faculty Publications, Department of Psychology by an authorized administrator of DigitalCommons@University of Nebraska - Lincoln. 
Published in Journal of Adolescent Research 2:4 (1987), pp. 383-392. Copyright (C) 1987 Sage Publications. Used by permission. http://jar.sagepub.com/

This research was supported by grant MH 30252138142 to Anne C. Petersen. We gratefully acknowledge the work of the entire staff of the Early Adolescence Study as well as the contributions of the young adolescents who participated in the research. We are also grateful to Diane Ruble and Lawrence Stricker for their helpful comments on an earlier draft of this paper.

\title{
Congruence between Objective and Self-Report Data in a Sample of Young Adolescents
}

\author{
Lisa J. Crockett, The Johns Hopkins University \\ John E. Schulenberg, Purdue University \\ Anne C. Petersen, The Pennsylvania State University
}

\begin{abstract}
Methodology texts frequently emphasize the limitations of self-report measures. Empirical information on the validity of self-report data, however, tends to be limited to particular topics and populations. This paper examines the validity of self-report data in a sample of young adolescents for whom objective and self-report data were available on course grades, height, and weight. A comparison of the two kinds of data generally supported the validity of the self-reports, although there was some evidence of response effects. It was concluded that while young adolescents exhibit some systematic errors in reporting, self-reports can provide a useful substitute for some kinds of objective data.
\end{abstract}

$\mathrm{M}$ ethodology texts frequently point to the potential inaccuracy of self-report measures (e.g., Cronbach, 1970; Fiske, 1980; Kerlinger, 1973). Generally, inaccuracy in self-reports stems from two sources: failures of recall and social desirability effects. Problems with recall reflect the respondents' capacity to encode and recall information about themselves. Failures of recall can reduce the accu- 
racy of reports, but such errors can be minimized by wording questions so that the respondent's memory is aided. In any case, we can usually assume that the errors occur randomly rather than systematically.

Social desirability effects represent a more serious threat to validity, since responses are by definition systematically biased. Respondents, wishing to present themselves in a favorable light, may (consciously or unconsciously) tailor their answers to make their behavior appear less deviant and more socially desirable (Bradburn, Sudman, \& Associates, 1980). Cronbach (1970, p. 40) summarized the problem as follows: "The crucial problem with self-report, if it is to be interpreted as a picture of typical behavior, is honesty... .Even when [the respondent] tries to be truthful we cannot expect him to be detached and impartial. His report about himself is certain to be distorted to some degree."

Despite the problems with self-report measures, there are times when more "objective" methods (e.g., direct observation) are not available to the researcher. This is frequently the case when the sample includes school-aged children, since parents or school administrators may prohibit the use of objective methods of assessment. In other cases, the expense of direct assessments may be prohibitive. Finally, some aspects of experience (e.g., attitudes, perceptions, moods, or feelings) are by nature subjective and are most appropriately assessed through self-reports Since self-report is often the most convenient (or only) research alternative, it becomes important to investigate the validity of self-report data in order to determine when and how such data can be used.

Because reliability of recall and the influence of social desirability may change over the course of development (e.g., Bray, Hersh, \& Turner, 1985; Foley \& Johnson, 1985; Froming, Allen, \& Jensen, 1985; Kunzinger, 1985), the validity of selfreport data and the magnitude and sources of errors in reporting are likely to differ at different points in the life-span. Thus, validity of self-reports cannot be generalized across age groups and topics of inquiry. Validity must be examined separately for each age group of interest.

In the present paper, we examine the accuracy of self-report data in a sample of young adolescents. Self-report and objective data were obtained on two topics: course grades and size as indexed by height and weight. Importantly, these data were obtained at two points in time (seventh and eighth grades), making possible an examination of the reliability of any observed response effects.

\section{Self-Reported Grades}

A number of large cross-sectional studies with high school and college students have demonstrated that self-reported grades can be highly accurate (see Baird, 1976 for a review). In a study of college-bound high school students, correlations between self-reported and actual grades exceeded .80 (Maxey \& Ormsby, 1971). The few studies involving younger adolescents indicate a similar level of accuracy in self-reported grades. In a study of over one thousand eighth grad- ers, the correlation between self-reported and school-reported grades was .84 or above for each of four course areas; when the grades across all four courses were summed, the correlation was .93 (Hanna, Bligh, \& Lenke, 1970).

The nature of errors in reporting has been examined in some studies of high school students. In these studies, most students have been found to report their grades accurately, while a small number overrepresent their grades and an even smaller number underrepresent their grades (e.g., Maxey \& Ormsby, 1971). Particular student characteristics have also been implicated in the tendency to report accurately. Gender is one such characteristic, with females being somewhat more accurate than males in reporting their grades; other characteristics associated with greater accuracy include higher achievement aspirations, higher grades, higher Scholastic Aptitude Test (SAT) scores, and a number of other demographic and school variables (see Baird, 1976).

\section{Self-Reported Height and Weight}

Height and weight are of particular interest in research on the validity of selfreports among young adolescents. Reliable information on height and weight is important for researchers interested in pubertal growth, since repeated measures of height and weight can be used to estimate age at peak growth (Bock, Wainer, Petersen, et al., 1973). At the same time, accurately reporting height and weight may be somewhat difficult for young adolescents, since many are undergoing rapid changes in these characteristics due to the onset of the pubertal growth spurt. Thus, we might expect some reporting errors due to lack of current information. Moreover, since the somatic changes of puberty appear to be salient to young adolescents (Clausen, 1975; Petersen \& Taylor, 1980; Tobin-Richards, Boxer, \& Petersen, 1983), there may be some tendency for boys and girls to distort their reports in line with culturally preferred physiques.

In the present study, analyses were performed to address two questions relevant to the accuracy and validity of young adolescents' self-reports of course grades, height, and weight.

1. How valid are the self-report data? Specifically, how large is the correlation between reported and actual values?

2. Do errors in the self-reports reflect random error or is there evidence of systematic bias in reporting? For example, is there a systematic tendency toward overestimating or underestimating? Similarly, are gender and grade level associated with errors in reporting?

Sample

\section{Method}

The data presented here came from a larger study of biopsychosocial development in early adolescence (e.g., Petersen, 1984). Two random samples of sixth 
graders representing successive birth cohorts were drawn from two suburban school districts in the Midwest. The two cohorts were each followed longitudinally for three years in accordance with a cohort-sequential longitudinal design (Bakes. 1968: Schaie, 1965). During the three years, individual interviews and group assessments were conducted semiannually (in the spring and fall of each year). A total of 335 students participated in the study, representing 80 percent of those invited to participate. (See Richardson, Schulenberg, Galambos, \& Petersen, 1984, for an in-depth description of the sample.)

The analyses for this paper are based on data from the 253 students in the two cohorts who completed at least four of the interviews and attended at least four group assessment sessions. This longitudinal sample has not been found to differ from the full sample on any variable. Since the self-report data to be analyzed here were not obtained in sixth grade, analyses are restricted to data from seventh and eighth grade. In addition, we will focus only on the data obtained from spring interviews. Finally, because of reduced sample sizes for height and weight data (described below) and because consistent cohort differences have not been found. the two cohorts were combined for these analyses.

\section{Measures}

Course grades. In seventh and eighth grade, the young adolescents were asked about the grades they typically received in school. During the spring interviews they were asked, "What grade to you get most?" In seventh grade, responses were coded on a seven-point scale; in eighth grade, the scale was extended to eight levels to enable greater precision.

Students were asked about their typical (i.e., modal) grades because this appeared to be an easier task for them than recalling their grades in specific courses or attempting to estimate their grade point average (GPA) at the time of the interview. The task of reporting was kept simple in order to minimize errors of recall and to avoid any computational errors (as might occur in attempting to estimate GPA). At the same time, it was important to validate the self-reports against an appropriate "gold standard" for school achievement. The standard employed was each student's GPA based on grades received in the core junior high subjects (i.e. English, Math, Science, and Social Studies). In both school systems, English was divided into courses in Literature and Language Arts; therefore, grades received in these two areas, plus those in Math, Science, and Social Studies were included. Course grades in these five subject areas were obtained from school records. Because both school districts used "+" and "-" to qualify the standard letter grades, students' grades were converted to a 12 point numerical scale ranging from 11 for

${ }^{1}$ For the seven-point scale, $1=$ mostly $F s ; 2=$ mostly Ds; $3=$ mostly $C s ; 4=$ mostly $C s$ and Bs: 5 $=$ mostly Bs: $6=$ mostly As and Bs; and $7=$ mostly As. For the eight-point scale, $1=$ mostly Fs; 2 $=$ mostly Ds; $3=$ mostly $C s$ and Ds; $4=$ mostly Cs: $5=$ mostly Bs and Cs; $6=$ mostly As and Bs; and $8=$ mostly As
"A" to 0 for "F." Final grades in the five subjects were averaged to yield an estimate of each student's grade-point average for each year of the study.

Height and weight. In the seventh and eighth grade interviews, the young adolescents were asked to report their current height and weight. Actual height and weight measurements were also available for the adolescents in one of the participating school districts. In this district the school nurse measured each student's height and weight in the winter of every year.

RESULTS

\section{Validity of the Self-Report Data}

To assess the criterion validity of young adolescents' reports of their course grades, height and weight, correlations between reported and actual values were examined for each variable. The Pearson Product moment coefficients appear in Table 1. The correlations were uniformly high: for course grades, the coefficients ranged from .70 to .84 (median $r=.76$ ); for height and weight, they were .90 and above (median $r=.94)$. All coefficients were significantly different from zero ( $p$ $<.0001)$.

TABLE 1

Correlations between Self-Reported and Actual Values

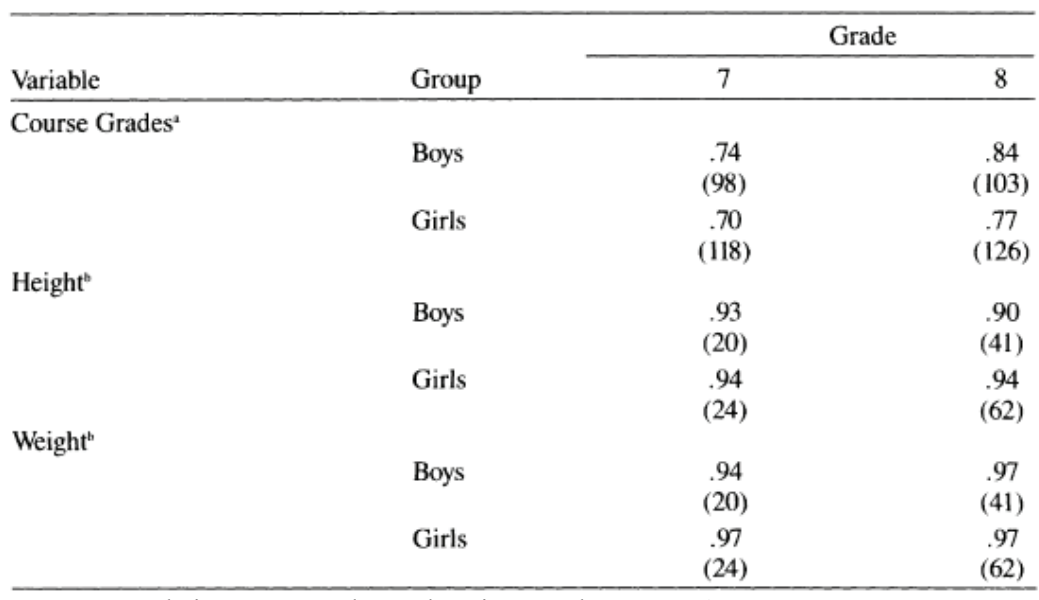

Pearson correlations were used. Numbers in parentheses are $N$ 's.

${ }^{a}$ Students were asked to report the grade they actually received. Actual GPA was calculated from final grades in five course areas.

${ }^{\mathrm{b}}$ Seventh grade data were available from only one cohort; eighth grade data included both cohorts. 


\section{Evaluation of Bias}

Bias was assessed by examining the distributions of errors in reporting by gender and grade level. In the case of random error one would expect errors to be distributed uniformly, with an equal amount of overestimation and underestimation. On the other hand, distributions skewed towards weight overestimation or underestimation would be evidence of bias. Simple difference scores were computed for course grades, height, and weight, by subtracting actual from reported values. Thus, a mean difference score significantly greater than zero would indicate a bias towards overestimating, and a mean difference score significantly less than zero would indicate a bias towards underestimating. Prior to computing difference score $\$$ for course grades, self-reported and actual values were rescaled into a common metric, so that the difference scores would not be inflated due to differences in the scale ranges. Specifically, the 12-point GPA scale was rescaled to fit the shorter self-report scale.

Difference scores for boys and girls at each grade level are presented in $\mathrm{Ta}-$ ble 2. As is evident from the table entries, the mean difference scores for grades and height were positive and significantly different from zero for boys and girls at both grade levels; thus, there was a general tendency to overestimate course grades and height. For boys at each grade level, the mean difference score for weight was also positive and significant. For girls, however, the difference score for weight was negative at both grade levels (although significant only in eighth grade). Thus, among girls there was a tendency to underestimate their weight.

TABLE 2

Summary Statistics of the Difference Scores Showing the Discrepancy between Reported and Actual Values

\begin{tabular}{|c|c|c|c|c|c|c|c|}
\hline \multirow[b]{3}{*}{ Variable } & \multirow[b]{3}{*}{ Group } & \multicolumn{6}{|c|}{ Grade } \\
\hline & & \multicolumn{3}{|c|}{7} & \multicolumn{3}{|c|}{8} \\
\hline & & $N$ & Mean & $(S D)$ & $N$ & Mean & $(S D)$ \\
\hline \multicolumn{8}{|c|}{ Course Grades" } \\
\hline & Boys & 98 & .48 & $(.96)^{\prime}$ & 103 & .78 & $(.87)^{\circ}$ \\
\hline & Girls & 118 & .31 & $(.83)^{+}$ & 126 & .49 & $(.86)^{\prime}$ \\
\hline \multicolumn{8}{|l|}{ Height" } \\
\hline & Boys & 20 & 1.00 & $(1.21)^{\circ}$ & 41 & .78 & $(.85)^{\circ}$ \\
\hline \multicolumn{7}{|l|}{ Weight" } & $(.99)^{\circ}$ \\
\hline & Boys & 20 & 3.70 & $(6.25)^{\circ}$ & 41 & 2.49 & $(5.51)^{\circ}$ \\
\hline & Girls & 24 & -1.13 & $(6.08)$ & 62 & -2.34 & $(5.16)^{\circ}$ \\
\hline
\end{tabular}

Difference scores were computed as the actual value subtracted from the reported value.

${ }^{\text {a }}$ Students were asked to report the grade they usually received. Actual GPA was calculated from Final grades in five course areas.

${ }^{\mathrm{b}}$ Seventh grade data were available from only one cohort: eighth grade data included both cohorts. Height entries are based on inches; weight entries are based on pounds.

* Mean difference score is significantly different from zero $(p<.05)$.

\section{Gender and Grade Level Effects}

Bias was further investigated by testing for gender and grade level difference in errors. Specifically, repeated measures ANOVAs (with grade level being a within-subject repeated factor) were used to determine whether the mean difference scores varied significantly by gender and grade level. For course grades, significant effects were found for both gender $(F(1,202)=6.54, p<.011)$ and grade level $(F(1,202)=7.11, p<.003)$, with the mean difference score being significantly higher among boys than among girls and higher at eighth grade than at seventh. Thus, boys overestimated their grades more than did girls, and the general tendency towards overestimating was greater in eighth grade than in seventh. The gender by grade interaction was not significant.

For height, neither the main effects nor the interaction term was significant, indicating that boys and girls overestimated their height to a similar degree and that the degree of overestimation was similar in seventh and eight grade. For weight, only the gender effect was significant $(F(1,37)=7.86, p<.008)$, with the mean difference score being significantly higher for boys than for girls.

\section{Discussion}

The analyses reported in this paper address several issues related to the validity of young adolescents' self-reports. The level of validity was examined by correlating self-reported and actual values of height, weight, and course grades, and bias was examined by analyzing systematic tendencies toward overestimation or underestimation in the self-report data and by testing for gender and grade level differences in the amount of bias.

\section{Validity}

The results largely support the validity of young adolescents' self-reports, although some errors in reporting were observed. Correlations between self-reported and actual values ranged from .70 to .97 with 50 percent to 70 percent of the variance in self-reported grades being attributable to actual GPA, and 80 percent to 95 percent of the variance in self-reported height and weight being attributable to actual values. The high correlations obtained with height and weight provide strong evidence for the validity of young adolescent's self-reports in these domains. The evidence concerning course grades is somewhat weaker, since it may be argued that correlations of .70 to .84 do not indicate a particularly high level of agreement.

\section{Evidence of Bias}

Evidence of systematic errors in the self-report data was also obtained. An analysis of simple difference scores revealed small but statistically significant amounts of overestimation and underestimation associated with boys' and girls' reports of their course grades, height, and weight. The observed gender and grade 
level effects provide additional evidence of bias, since errors significantly associated with these (or other) variables cannot be random. For each gender the tendency to overestimate or underestimate was consistent across the two grade levels; thus, the observed response effects appear to be reliable, despite some minor variation in the size of effect.

Some of the discrepancies between self-report and objective data observed in the present study could be an artifact of the measurement procedures employed. First, students were asked to report their typical (i.e., modal) grades, but an average grade (final GPA) was used to represent actual values. Second, actual grades were coded on a 12-point scale and self-reported grades on a seven- or eight-point scale; thus, there may have been some discrepancy due to the use of different metrics. Third, GPA was computed from grades received in five important subject areas, but grades in other areas were not taken into consideration. Each of these factors could have decreased the correspondence between self-reported and actual grades. Thus, it is not surprising that the correlations obtained in this study were lower than those observed in prior studies of school grades (e.g., Hanna et al., 1970), in which the questions asked of the students more closely matched the objective data that was employed.

Measurement artifacts may also have contributed to the discrepancies between self-reported and measured height and weight. The self-report data were obtained up to four months after the annual measurements were taken. The height and weight of boys and girls, especially those in the midst of their growth spurts, could have increased in the intervening period, thus producing an apparent tendency toward overestimation in the self-reports. (Thus, intervening growth may help account for the overestimation found with height, although it cannot account for girls' tendency to underestimate their weight). Based on these considerations it seems most reasonable to view the correlation coefficients reported here as conservative estimates of the correspondence between self-reported and true values in the domains of course grades, height, and weight.

The gender difference in overestimating grades is in keeping with earlier findings on self-reported course grades among high school students (Maxey \& Ormsby, 1971). It is also consistent with much of the literature on performance attributions and expectations: many of these studies indicate that males are more likely than females to overestimate their performance in a variety of achievement domains, especially those perceived to be male domains (Gitelson, Petersen, \& Tobin- Richards, 1982; Lenny, 1977). Thus, the greater tendency for boys in this sample to overestimate grades may reflect a more general proclivity among males to overestimate their performance.

The gender difference in estimating weight fits well with the existing literature on preferred body types. For females, the cultural ideal emphasizes slimness (e.g., Faust, 1983); thus it seems reasonable that girls would tend to underestimate their weight. For boys, on the other hand, larger size may contribute to athletic ability which is in turn associated with high social status (e.g., Savin-Williams, 1979). Thus, bulk is more likely to be valued by boys.
In sum, the present results suggest that young adolescents' self-reports can provide a reasonably valid substitute for objective data on height, weight, and course grades. Importantly, however, the correspondence between self-reports and objective data was not perfect; response errors were present and some portion of the error was systematic. Thus, in choosing self-report methods researchers studying young adolescents must determine how much error they can tolerate; if extreme precision is required, then an attempt should be made to obtain objective measurements. If this is not possible, it would appear that self-report data can be a useful alternative.

\section{REFERENCES}

Baird, L. L. (1976). Using self-reports to predict student performance. Research Monograph Number 7. New York: College Entrance Examination Board.

Baltes, P. B. (1968). Longitudinal and cross-sectional sequences in the study of age and generation effects. Human Development, 11, 145-171.

Bock, R. D., Wainer, H., Petersen, A. C., Thissen, D., Murray, J., \& Roche, A. (1973). A parameterization for individual human growth curves. Human Biology, 45, 63-80.

Bradburn, N. M., Sudman, S., \& Associates. (1980). Improving interview method and questionnaire design. San Francisco, CA: Jossey-Bass.

Bray, N. W., Hersh, R. E., \& Turner, L. A. (1985). Selective remembering during adolescence. Developmental Psychology, 221, 290-294.

Clausen, J. A. (1975). The social meaning of differential physical and sexual maturation. In S. E. Dragastin \& G. H. Elder (Eds.), Adolescence in the life cycle: Psychological change and social context (pp. 25-47). Washington, DC: Hemisphere.

Cronbach, L. J. (1970). Essentials of psychological testing (3rd. ed.). New York: Harper \& Row.

Faust, M. S. (1983). Alternative constructions of adolescent growth. In J. Brooks-Gunn \& A. C. Petersen (Eds.), Girls at puberty: Biological and psychosocial perspectives (pp. 105-125). New York: Plenum.

Fiske, D. W. (1980). When are verbal reports veridical? New Directions for Methodology of Social Behavioral Sciences, 4, 59-67.

Foley, M. A, \& Johnson, M. K. (198.5). Confusions between memories for performed and imagined actions: A developmental comparison. Child Development, 45, 1145- 1155

Froming, W. J., Allen, L., \& Jensen, R. (1985). Altruism, role-taking, and self-awareness: The acquisition of norms governing altruistic behavior. Child Development, 56, $1223-1228$.

Gitelson, I. B., Petersen, A. C., \& Tobin-Richards, M. H. (1982). Adolescents' expectancies of success, self-evaluations, and attributions about performance on spatial and verbal tasks. Sex Roles, 8, 411-419.

Hanna, G. S., Bligh, H. F., \& Lenke, J. M. (1970). Student-reported grades as predictors. Personnel and Guidance Journal, 48, 465-468. 
Kerlinger, F. N. (1973). Foundations of behavioral research (2nd ed.). New York: Holt, Rinehart, \& Winston.

Kunzinger, E. L. (1985). A short-term longitudinal study of memorial development during early grade school. Developmental Psychology, 21, 642-646.

Lenny, E. (1977). Women's self-confidence in achievement settings. Psychological Bulletin, 84, 1-13.

Maxey, E. J., \& Ormsby, V. S. (1971). The accuracy of self-report information collected on the ACT Test Battery: High school grades and items of non-academic achievement. ACT Research Report No. 45. Iowa City, IA: Author.

Petersen. A. C. (1984). The Early Adolescence Study: An overview. Journal of Early Adolescence, 4, 1-4.

Petersen, A. C., \& Taylor, B. (1980). The biological approach to adolescence: Biological change and psychological adaptation. In J. Adelson (Ed.), Handbook of adolescent psychology (pp. 117-155). New York: Wiley.

Richardson, R. A,, Galambos, N. L., Schulenberg, J. E., \& Petersen, A. C. (1984). Young adolescents' perceptions of the family environment. Journal of Early Adolescence 4, $131-153$.

Savin-Williams, R. C. (1979). Dominance hierarchies in groups of early adolescents. Child Development, 50, 923-935.

Schaie, K. W. (1965). A general model for the study of developmental patterns. Psychological Bulletin, 64, 92-107.

Tobin-Richards, M. H., Boxer, A. M., \& Petersen, A. C. (1983). The psychological significance of pubertal change: Sex differences in perceptions of self during early adolescence. In J. Brooks-Gunn \& A. C. Petersen (Eds.), Girls at puberty: Biological and psychosocial perspectives (pp. 127-154). New York: Plenum. 